\title{
Revisiting Human's Place and Role in Humanitarian Anthropocentric Research of Language and Communication
}

\author{
Helena Lugowska ${ }^{1, *}$
}

\author{
${ }^{1}$ Department of Russian Language and Intercultural Communication, Pridnestrovian State University named after Taras \\ Shevchenko, Tiraspol, Pridnestrovie (Transdnisteria) \\ *Corresponding author. Email: lugowska@spsu.ru
}

\begin{abstract}
The author contemplates on the human's place in the language and the communicating. He gives the analysis in terms of anthropocentric and linguistic paradigm, philosophical and cultural knowledge. The author suggests determining the human role in the language with term anthropo. It has a language and culture manifestation through iconization, indexation and symbolization; it concerns the philosophical problems of consciousness, the self and not-self identifying. The problem is actually toward metamodern as the present paradigm of synthetic thinking, which leads to the transformation of subjectivity (agency). The subjectivity spread in the language gradually disappears as a paradigmatic structure, giving up its properties to the language realized in communicating. The sign anthropo has the cognitions as a content plan and the person in his functionality as an expression plan. The anthropo as communicating the self and not-self is the bit of anthropocentrical information that designates ontologically the social existence of human, culture, language, communicating and consciousness.
\end{abstract}

Keywords: anthropo, human, culture, language, communicating, consciousness, metamodern

\section{INTRODUCTION}

A human structurizes the reality where he configures itself like the self (the object) while having gained the ability to call everything that exists, i.e. having a linguistic capacity as essential. The language system is materialized through a person, and a person in return constructs the culture as an appositional to the language system. And in this sense person (human) turns out to be the element without language and culture correlations are impossible and meaningless. (Read more about this here: [1])

However, using in this argument the term person if not human is incorrect because of its ambiguity, therefore, we suggest using the term anthropo when determining the human role and its place in the sign structure of language and culture under the character of anthropocentric entities. We insist on using this term also because according to the definition in the Cambridge dictionary the natural language is the language that has developed in the usual way as a method of communicating between people (emphasis added), rather than language that has been created, for example for computers [2].

\section{THE HUMAN'S PLACE IN THE NATURAL LANGUAGE}

One fine day my teacher and friend professor of philosophy tells me that there is no any human in modern researching le parole. At that particular time, I was arguing him about the perspectives of the modern anthropocentric paradigm of humanities knowledge. I was sure and I tried to make him sure that such an approach does help scientists in their dissection of human speech ability. I was telling him about the structure of linguistic persona [3], I was trying to show him that an anthropocentric (communicative and cognitive) linguistic paradigm is that return the human into the language.

The comparative method in linguistic, I continued to tell, presupposes the human to be the conduit for language exploration. The human, in this case, is not somebody who explore. The human is one who while using the investigated subject can distinguish some general details and specifies in such a way, the human wants to identify something unknown. And he does it customarily - he identifies the form tralatitiously. That is not bad because he can abstract away his influence on the subject - langue, but can he? Human's knowledge, 
human's interpretation way, human's goal of research - all of them let the human to turn the attention only to a limited part of a multidimensional phenomenon which human language is, make the research some subjective one. But where is the human itself in this idea?

Every research needs at least three components the who (researcher), the whom for (target of research) and the wherewith (research tool). And you know there are only two real components - the target of research and research tools - while trying to explain the essence of a human language one has to use studied phenomenon as a tool at the same time. And if we take it to step further, we can see that only one component is existing there - the tool itself. Because they're not real existence of langue without parole and there is no parole without somebody who can, who wants and who do speak.

But then it was not so evident and at any rates, it was not crucially important. There were some tools, and there was data for the study. Any sphere of human activities is inconceivable without language. That is why the question about the coincidence of the subject for study and tooling was considered looking from a different angle. The taxonomical aspect allows investigating of language phenomenon without research of its functionality and substance details being focused only on the general idea of form.

Historically the comparative method was a rightful approach to investigate - in the first place it is necessary to define the goal of research. And comparative linguistic did it. There remained a lot of questions and secrets about human language, but it was the main achievement for humans to distinguish most world languages in their variety.

So, when one can see the research goal, he wants to understand its structure; he wants to explore its organization. And the same structural linguistics did (or does?)

And now what about the above questions who, whom for and wherewith for the structural linguistics? The same researcher investigates the same goal - the language, but now he does it internally as if he was inside the language. And could it be that he put himself into the abstract phenomenon like extraneous interference? No, he should be similar to this phenomenon and he is. That's why he is not a beholder, not a researcher, but only again he is the language phenomenon (in the form of linguistic persona or homo communicans).

I think you know where I'm going. There is no true functionality in structural methodology in linguistic studies. We try to describe this mystical phenomenon and try to find in it and in its description ourselves, but where we are? Is it possible to understand that you concern the elephant wherever you can see only his skeleton and the processes which help you understand how you can see it (something like The parable of the blind men and an elephant).

Is it possible to find an anthropo in such research? Yes, there it is. The knowledge about the necessity of skeleton (structure) and function particularities (functional, pragmatic and cognitive communicative language research approaches) can't show us an anthropo itself. But one can imagine language system and it will be anthropic recept and percept; one can investigate language functionality, and this will be precisely individual which phonological processing ability, language capacity and linguistic competence create some special aspects of language functioning while being in the pockets of these aspects.

\section{ANTHROPO IS IN THE BEHOLDER'S EYE}

Our discourse converges on linguistic. Let us philosophize a little about the modern anthropocentric paradigm of humanities knowledge in traditional terms of langue and parole [4]. Whose points of view are noteworthy in this sphere? In the first instance, we must mention W. von Humboldt with his thesis about the human language as a rule-governed system. The language system, his contention is, rather than just a collection of words and phrases paired with meanings and the relationship between the linguistic worldview and the transformation and maintenance of this worldview by individual speakers. Why is it so? Because the natural language itself is a creation of nature - the nature of the human mind. $<\ldots>$ The true difficulty of creating a language is not so much in establishing a hierarchy of an infinite number of interrelated relationships, but in the incomprehensible depth of the simple action of reason, which is necessary for understanding and generating the language even in its individual elements. $<\ldots>$ It is impossible to learn, it must be intrinsic to human [5].

We must mention F. de Saussure from whose perspective, we can distinguish between two fundamental forms of language: natural or first-order language, on the one hand, and formal or second-order language, on the other [6].

We cannot fail to notice Noam Chomsky who treats language as a uniquely human, biologically based cognitive capacity human language appears to be a unique phenomenon. But surely the classical questions of language and mind receive no final solution, or even the hint of a final solution, from the work that is being actively pursued today. Nevertheless, these problems can be formulated in new ways and seen in a new light [7].

Let us now revise the design of an anthropo with the help of this knowledge... No idea. Anyone cannot reconstruct the human, man, individual when rummages 
around in langue and parole either in socio-, psycho-, neuro-, cognitive etc. features of anthropo that is only the instrument asset - some language speaker.

So wheresoever is anthropo in language?

The sign essence of the language and culture phenomena and their interdependence allows to consider them as elements (signs) of the superordinate sign system, as a complex sign. The anthropo essence is reflected in culture, culture is expressed in language, anthropo is signified, manifests through language. This sign system component - anthropo - has its language and culture manifestation through iconization, indexation and symbolization (due to Ch. S. Peirce).

An anthropo representamen represents symbolic, linguistic, or artificial human portrait with no subject of a sign and an interpretant.

The anthropo as a semiotic object is a special or partial object indicative of thing, event, relationship, quality, law, argument, etc., and can even be fictional [8]. In this sense everything that a person deals with, his world view is only a sign about human but ultimately not aside from the human.

And finally, the anthropo as an interpretant sign is the sign's more or less clarified meaning of hominal and humanistic, a kind of form or idea of anthropic.

If we admit the term anthropo to be a sign as one of semiosis elements then the cognitive component (cognitions) will be a content plan and the individual in his functionality will be an expression plan of this sign.

But when do all these elements manifest? Anthropo - the sign system component materializes with communicating only because of the social essence of communicating and social existence of humanity itself.

And now there is another big problem: has the human its communicating or the communicating itself has a human as one of the communicating's components?

\section{HUMAN VS COMMUNICATION}

The new century further deepened the existing antinomies and proposed its ones - in particular, universalization in all spheres of human life intensified the processes of individualization and uniqueness was considered as a characterological sign of community. Such metamorphoses caused new methodological thinking, trying to overcome antinomies.

The beginning of the 21 st century was characterized by philosophy and methodology of science close attention to the problem of the culture deepest crisis, which manifested itself in postmodernism. The requirement for the integrity of consciousness, dictated by the fatigue of the generation of postmodernism from discrete, fragmented and kaleidoscopic thoughts and reasoning concerning reality, is due to the orientation of cognitive processes of modern person to overcome the antinomy of analyticity and holisticity. Moving from a parallel analysis of the most complex secrets of being in individual disciplines to collaborative research in transdisciplinarity is not just a requirement. The transdisciplinarity combines traditional forms of disciplinary scientific knowledge with a usual, communicative, personal and other types of social experience focused on wide knowledge [9]. Similar epistemological manifestations of the modern scientific paradigm, in particular the linguistic one, are caused by the transformation of agency (subjectivity) as all that relates to the self and represents its uniqueness.

The postmodern crisis of self (ego) reflected, recorded and comprehended such characteristics of its time as instability, variability, lability, fluidity, sensitivity to contexts. The new paradigm of metamodernism without denying the achievements of the previous paradigm, dissolved postmodernism. It becomes the postmodern logical consequence, and deprived the postmodernism self of its agency, denying him even the fact of the death.

The death of the 'subject' (the self) in the postmodern paradigm did not affect the very concept of agency, because, having rejected the subjectivity of the author or hero, postmodernism killed only the form of representation, but not the way itself. Anthropocentrism and modernist inertia, even in postmodernism, could not exist outside of subjectivity. The subject (the self) was replaced by a distributed subject — irony. Such a distributed essence was very unstable, the subject now gathered like a mosaic, now it crumbled again and was restructured kaleidoscopically. This experience perhaps caused the very oscillations representative of the metamodern. This antinomy expressed by the unity of and concurrently if not opposite then multidirectional processes is a vivid example of a peculiar unstructured (spontaneous) transdisciplinarity and transscientificity.

The correlation of postmodernism and the postnonclassical science and the epistemology of lastmentioned asserts the relativity of the science dichotomies and their relevance in the application to the methodology of scientific research. These dichotomies determine the basic principles such as cultural studies and constructiveness and conventionality. Moreover, it is necessary to mention that the problem of consciousness remains the major philosophical problem of modern science. The problem of the relation between consciousness and language as a cognitive process has recently gained significant interest and evoked numerous discussions. The reason may lie in the fact that - on the one hand - language has always been considered one of the most important mental (and cognitive) faculties; on the other hand, one can observe 
growing interest in consciousness within cognitive science [10].

Postmodernism didn't become the reflective end of the modern world only, it marked the cultural and psychological transformations era (the last third of the 20th century), the most striking exponent of which was metamodern. Metamodern recognized as a new paradigm of thinking, as a special state of society in its transition from irony to sincerity, from simulacrum as a way to realize objective reality to finding one's path without denying the world, from denying identity to going beyond it, dissolves agency in the general for the self and the not-self of reality, passing undeniable truth through subjective one, through symbolic and mythological perception. And the cognition as the basic mechanism of human activity and human thinking processes are metaphorical.

Thus, non-linearity, the multidimensionality of scientific analysis, redefinition of methods and methodologies as epistemological manifestations of the metamodern stage in science in general, as well as in linguistics, in particular, act as manifestations of transdisciplinarity due to the transformation of subjectivity as all that relates to the self and determines its uniqueness. The main tendency of the transformation of subjectivity in the metamodern is synthetic thinking - to integrity through antinomies. Within the framework of which the subjectivity spread in the language gradually disappears as a paradigmatic structure, giving up its properties to the language, they realize in communicating [11].

The development of cognitive linguistics with these problems of the correlation of language and consciousness has become an important area of recent times. Considering the relationship of certain cognitive abilities of a person with natural language, cognitive linguistics goes far beyond the structural or comparative-historical paradigms of linguistics, but inevitably uses all the achievements of scientific thought obtained in the framework of these paradigms.

Human cognition on the path to the formation of new cognitive mechanisms and layers, among which logical, verbal and symbolic thinking, realized through language, tradition and morality, together with a special human ability to self-knowledge and reflection, developed in the post-postmodern era in a complex synthetic structure, which is both analytical and holistic, and today it is the main antinomy that metamodern is trying to overcome.

An attempt to consider a human with its speech ability as the self of communicating, which at the same time turns out to be the self of the language and culture, leads to one-sidedness in the conception of communicating within the framework of the modern anthropocentric paradigm of humanitarian knowledge.
A human appears to be a kind of creator of converse as the self of the communicative process, and in any dialogical interaction he is responsible for its process and its outcome. Here, special attention is paid to the correct selection and organization of linguistic means proper, considering all extra-linguistic factors (functional and stylistic aspect), national and cultural characteristics (ethnocultural aspect), mental characteristics (cognitive aspect).

But human is not the self who determines the choice of the moment for the communicating embodiment, but communicating itself, in its moment of embodiment, determines a certain set of unique characteristics of all its components, including the communicants themselves. Such an understanding leads a human out of the ego category. The speaker is likened to speech as a method of embodiment and language as its mechanism in converse understanding.

The division into the self and not-self within the framework of the traditional understanding of communicating contradicts the understanding of communicating itself as perception, represented in a symbolic form. I consider communicating to be perception itself, and only the communicative situation, i.e. its materialization conditions, which includes a speaking person as an owner of the mechanism for communicating, which offers its information coding system, allows communicating results in texts and discourse.

\section{CONCLUSION}

The modern anthropocentric paradigm of actual humanities knowledge suggests the researcher an approach which expects some modern understanding of 'anthropocentric'. Now it isn't a conception of human's cognitive mapping on the real world (because the author considers this phenomenon (cognitive map or mental map, mental model) to be the archetypical one) - an 'anthropo' cannot be sensible of anything but itself).

Now we are up against the question about how it is work. I mean the previous point of view on anthropocentric understanding like on the answer on the question about what is it. What extent to everything the individual can be sensible of is possible to describe in the terms of 'anthropocentric' this problem was brought to a close. But there is another important question how is it work. Now we are interested in cognitive and neurophysiological mechanisms of such an anthropocentrical approach to world view construction but bracket out the main existential problem - why is it so. All answers we could answer this question are deeply philosophical or esoterical and even quantum unfathomable mystery should give us a clue on the question... 
Transscience is a new philosophy on traditional grounds. The traditional paths to and within science, philosophical knowledge of the world require a review and qualitative changes toward acquiring signs of integrality and discreteness at the same time. while we are discussing trans science, it is a natural stage in the development of the philosophical and scientific thought of mankind. The direction and results of scientific and cognitive activity depend on the culture of which it is an integral element. The scientific world view and knowledge provide a cognitive basis for human activity in transforming the world and itself. The recognition of the role of beholder, whose personal interest in study object act upon not only the research results but also upon the researcher's method was getting through scientists' heads long after.

So, what is it - the 'anthropocentric', how is it work and why is it so? Using this line of reasoning one should advance the view for the anthropo as the self and not-self of communicating coincidently, as some quanta, the bit of anthropocentrical information that designates ontologically the social existence of human speech ability and linguistic competence, culture and language, cognitions and communicating.

\section{References}

[1] E.G. Lugovskaya, Culture - Anthropo - Language // Kazan Science, No. 9, 2019, Kazan Publishing House, 2015. 158 p. P.125-129. [in Russian]

[2] Essential British English Dictionary: URL: https://dictionary.cambridge.org/

[3] Yu.N. Karaulov, Russian language and linguistic identity. LCI, URSS Editorial [e-book] 2010, 264 p. [in Russian]

[4] Ferdinand de Saussure, Course in General Linguistics, eds. Charles Bally and Albert Sechehaye with Albert Reidlinger, trans. Wade Baskin, New York: Philosophical Library, 1959.

[5] Humboldt, Wilhelm von, Ueber das vergleichende Sprachstudium in Beziehung auf die verschiedenen Epochen der Spraehentwieklung, 1820. (Report, read June 29, 1820) Quoted by: Humboldt, Wilhelm von, Selected Works on Linguistics. Translation from German under the editorship and with the foreword by Doctor of Philology prof. G.V. Ramishvili. 2nd edition, Moscow Progress Publishing Group, 2000.

[6] S. Susen, (2018), Saussure, Ferdinand de. In: B. S. Turner, C. Kyung-Sup, C. F. Epstein, P. Kivisto, W. Outhwaite \& J. M. Ryan (Eds.), The Wiley Blackwell Encyclopedia of Social Theory. (pp. 2001-2006). Chichester, UK: John Wiley \& Sons.

[7] Noam, Chomsky, Linguistic Contributions to the Study of Mind (Future). Source: Language and Mind. publ. Harcourt Brace Jovanovich, Inc., 1968. Transcribed: in 1998 by Andy Blunden, proofed and corrected February 2005. URL: https://www.marxists.org/reference/subject/philosophy/works/u s/chomsky.htm

[8] Peirce: EP, $1992+1998$, The Essential Peirce. Selected Philosophical Writings, Vol. I (1867-1893), Vol. II (18931913) (ed. by Nathan Houser and Christian Kloesel, Peirce Edition Project). Indiana University Press, Bloomingtion and Indianapolis.

[9] L.P. Kiyashchenko, Philosophy of Transdisciplinarity, monograph / L.P. Kiyashchenko, V.I. Moiseev; Grew up. Acad.
Sciences, Institute of Philosophy. Moscow IFRAN, 2009. 208 p [in Russian] URL https //znanium.com/catalog/product/357159

[10] P. Konderak, Between Language and Consciousness: Linguistic Qualia, Awareness, and Cognitive Models Studies in Logic, Grammar and Rhetoric. Vol: 48 (61) pp: 2016. DOI 10.1515/slgr-2016-0068

[11] George, Lakoff, Mark, Johnson, Metaphors We Live by, University of Chicago Press, 2003. 191 p 